\title{
Mutual interference of bridge piers placed in staggered arrangement on scour depth
}

\author{
M.Beg \\ Department of Civil Engineering, Z. H. College of Engineering and Technology, AMU, Aligarh,202003, U.P. \\ India
}

\begin{abstract}
The work reported herein is concerned with a carefully controlled extensive experimental study of local scour around a group of bridge piers placed in staggered arrangement with constant angle of attack and varying radial pier spacing in uniform sediment at varied pier spacing under steady uniform flow clear water scour conditions at flow intensity equal to 0.95 . The objective of present study is to investigate the effect of mutual interference of bridge piers placed in staggered arrangement on the scour depth. Present study reveals that the piers placed in staggered arrangement at close proximity have considerable mutual interference effect on scour depth. It is found that the downstream pier should be placed at radial pier spacing greater than six times the pier diameter since the effect of vortex shedding produced by front pier on rear pier is reasonably less.
\end{abstract}

\section{INTRODUCTION}

Scour is the process of lowering of river-bed around an obstruction due to removal of the bed material by erosive action of flowing water. In case of local scour the lowering of the riverbed occurs in the vicinity of the structure. In spite of significant amount of research on single pier scour, failure of many bridges has rekindled interest in furthering understanding of the pier group scour.

\subsection{Local scour at group of bridge piers}

In case of scour around group of piers, the presence of piers can generate a complex interaction in the hydrodynamic characteristics of the flow field near the piers themselves and therefore, lead to the occurrence and development of a scour process that is quite different from one which occurs around a single pier.

Local scour around a single bridge pier is affected by a large number of inter-dependant variables. The flow, sediment, pier characteristics and time are the main variables affecting this phenomenon. As a consequence of extensive research by several investigators on the phenomenon of local scour around a single bridge pier, a large number of design relationships have been bequeathed to the bridge designer. Notwithstanding this, many bridges still suffer damage by local scour. This is due to more intense complexities due to the mutual interaction of piers group. It indicates that in addition to the variables affecting local scour around a single pier, spac- ing of piers and pattern of piers' placement in the riverbed also affect the scour depth and scour hole characteristics around group of piers. One of the patterns of piers placement may have staggeed arrangement (Figure 1). Timonoff (1929), Garde. (1961), Basak et. al. (1975), Hannah (1978), Elliot, K.R. and Baker, C.J. (1985), El-Taher, R.M. (1984, 85), Shah (1988), Kothyari, U.C., (1989), Breusers and Raudkivi (1991), Garde, et. al. (1995), Vittal et. al. (1994), Babaeyan-Koopaei and Valentine (1999) and Mubeen Beg (2008) have made some studies on scour around group of piers.

Hannah (1978) identified four scouring process (reinforcing, sheltering, vortex shedding and compression of horseshoe vortices) which occur around two piers having their line of centres at an angle $45^{\circ}$ to the approach flow.

\subsubsection{Reinforcing}

It causes increased scour depths at the front pier. Bed material is continuously lifted from the base of the hole by the flow, which is not, however, capable of removing this material from the scour hole. When the downstream pier is so placed that the scour holes overlap, the bed level is lowered at the rear of the upstream scour hole. It is, thus, easier for the flow to remove material from this hole and it deepens. As the pier separation increases, the reinforcing effect decreases gradually and disappears when the maximum bed level between the piers returns to the undisturbed bed level. 


\subsubsection{Sheltering}

The presence of an upstream pier can cause a reduction in effective approach velocity for downstream pier. This reduction weakens the effect of horseshoe vortex and thereby reduces scour at the downstream pier. A second form of sheltering occurs if the material scoured from the upstream pier is deposited on the bed in front of the downstream pier. Flow is then deflected up from the bed near the downstream pier, which reduces the horseshoe vortex strength. As pier separation increases, the velocity deficit in the wake of the upstream pier disappears and the sheltering effect decreases. All the studies of scour around pier groups substantiate the existence of sheltering mechanism for small angles of attack.

\subsubsection{Vortex shedding}

Vortices shed from an upstream pier are convected downstream. When a second pier is so placed close to one of the vortex shedding paths, the vortices assist in lifting the material from the scour hole. The scouring potential of the shed vortex is a function of its convection speed and of the distance between the path and the affected pier. This effect, therefore, decreases more rapidly for piers in line with the flow than for those at angles of attack which place downstream piers on the paths traced by vortices shed by upstream pier.

\subsubsection{Horseshoe vortex compression}

When piles are placed transverse to the flow, each will have, except at very close spacing, its own horseshoe vortex. As pile spacing is decreased, the inner arms of the horseshoe vortices will be compressed. This causes velocities within the arms to increase with a consequent increase in scour depths. This compression also exists for piles in staggered arrangement.

\section{EXPERIMENTAL PROGRAMME}

Experiments were conducted in advanced hydraulics laboratory in Department of Civil Engineering, Z.H. College of Engineering and Technology, AMU, Aligarh, U.P., India. $33 \mathrm{~mm}$ galvanized steel circular cylindrical pier models were used in present study. Making the isolated pier scour depth as a base for evaluation of mutual interference, few experiments were also conducted at an isolated pier of the same diameter and with the same flow conditions as that used in the present study on mutual interference of bridge piers in staggered arrangement. Two pier models were set vertically in the sediment bed of the flume at constant angle of attack of $45^{\circ}$ and varying clear radial spacing between the piers $\mathrm{R} / \mathrm{b}=$ $0,1,2,3,4,5,6,7,8,9,10,11,12$. As shown in figure 1 , the two piers were so located in the flume sediment bed at a particular radial spacing and $45^{\circ}$ angle of attack that the perpendicular distances of their centers from the center of the flume were equal. The sediment bed around the piers was fairly leveled and the experiments were performed with the same procedure as that at the single pier. The temporal scour depth measurements during the experimental runs and detailed measurements of scoured area around the piers after stopping the experiments, were also be made in the same manner as that at single pier.

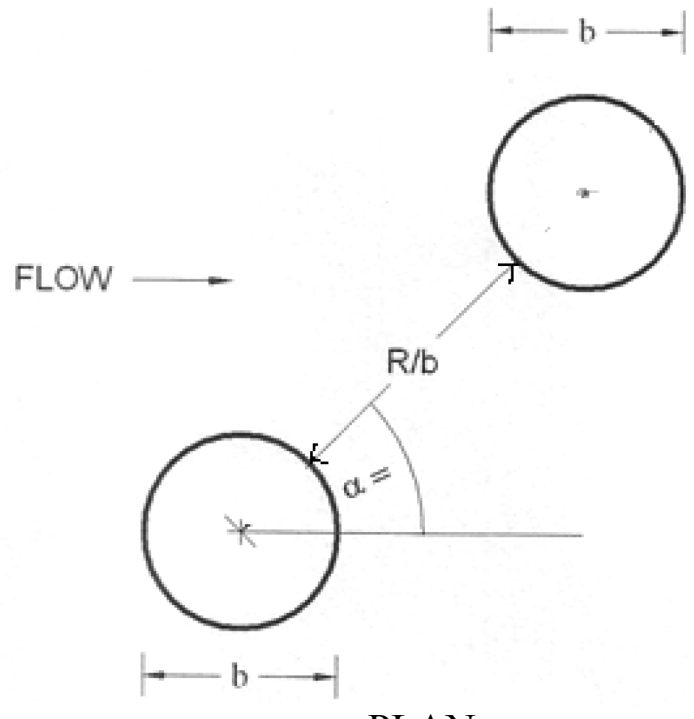

\section{PLAN}

Figure 1. Piers of same size in placed in staggered arrangement

The angle of attack of $45^{\circ}$ degrees was selected because, the effect of mutual interference is said to be maximum at this angle of attack as reported by Hannah (1978).

Tables 1 and 2 give the flow, sediment and pier parameters used in experiments.

Table 1. Properties of sediment and piers used in present study.

\begin{tabular}{|l|l|}
\hline $\mathrm{D}_{84.1}(\mathrm{~mm})$ & 1.03 \\
\hline $\mathrm{D}_{15.9}(\mathrm{~mm})$ & 0.73 \\
\hline $\mathrm{D}_{50}(\mathrm{~mm})$ & 0.95 \\
\hline Geo.- standard dev. $\sigma_{\mathrm{G}}(\mathrm{mm})$ & 1.187 \\
\hline Specific Gravity $\mathrm{S}_{\mathrm{s}}$ & 2.65 \\
\hline Pier size used Circular Piers & $33 \mathrm{~mm}$ \\
\hline Angle Of Repose $\phi$ & $32^{\circ}$ \\
\hline U/U $\mathrm{U}_{\mathrm{C}}$ & 0.95 \\
\hline
\end{tabular}

Table 2. Computed mean flow parameters.

\begin{tabular}{|l|l|}
\hline Discharge $\left(\mathrm{l}^{3} / \mathrm{s}\right)$ & 41.4 \\
\hline Depth Of Flow y $(\mathrm{mm})$ & 140.0 \\
\hline Mean Velocity U (m/s) & 0.391 \\
\hline Threshold Velocity U (m/s) & 0.412 \\
\hline Froude No. $\mathrm{F}_{f}$ & 0.333 \\
\hline Critical Froude No. $\mathrm{F}_{\mathrm{rc}}$ & 0.350 \\
\hline Average energy slope $\mathrm{S}_{0}$ & 0.001 \\
\hline
\end{tabular}

Since in present study clear-water experiments were conducted using coarse sediment of $0.95 \mathrm{~mm}$ median diameter, duration of 10 hours was considered adequate. Most researchers state that for a con$\operatorname{stant} U_{*} / U_{*_{c}}$, the influence of flow depth can be neglected for $y_{0} / b>2$ to 3 . 
To form a basis for analyzing results on group of piers placed in staggered arrangement, a series of experiments on $33 \mathrm{~mm}$ diameter single pier was also performed.

Each experiment commenced from a condition of still water at the predetermined flow depth over a leveled bed surface. The time of start of initial movement of sediment, and of water surface establishment were recorded. On the completion of the experimental run, the water supply to the flume was gradually stopped and the water from the flume was drained off carefully so that the scour holes and the scour patterns around the piers developed by the flow were not disturbed.

\section{DATA COLLECTION}

Detailed experimental data during the experimental runs and after experimental runs were collected The dynamic scour depths at the nose of piers were measured and recorded during the entire experimental runs at suitable interval of time. However, as each experimental run was over, scoured area around the piers was surveyed with point gauge and detailed static scour measurements were made and recorded. The length of scour holes at front and rear faces of upstream and downstream piers, width of scour holes at front faces of upstream and downstream piers, the areal extent of scour around the piers and the length of sediment deposition on rear face of upstream and downstream piers were measured and recorded. Photographs of scour holes and areal extent of scour were taken as shown in figure 2 .

\section{RESULTS AND DISCUSSION}

\subsection{Scour depth at front and rear piers}

Using the scour data collected in this study, the relative scour depths ' $d s_{c a(f)} / d s_{(i)}$ ' and ' $d s_{c a(r)} / d s_{(i)}$ ', where $\mathrm{ds}_{\mathrm{i}}$ is the scour depth at isolated single pier, observed at the upstream face of front and rear piers, plotted against radial pier spacing ' $R / b$ ' is shown in. figure 3. At radial pier spacing $R / b=0$, the two piers touching each other behaves like a single pier of more frontal width, the maximum scour depth is observed as $2.012 d s_{(i)}$. However, at radial pier spacing $R / b=1$, the scour depths at front and rear piers are observed as $1.35 d s_{(i)}$ and $1.38 d s_{(i)}$. respectively. This steep reduction in relative scour depths is due to a decrease in the frontal width caused by the gap between the two piers. At radial pier spacing $R / b>1$, the scour depth at rear pier is observed to be more than that occur at front pier. However, at pier spacing $R / b=12$, the scour depth at front and rear piers approach to that of an isolated pier. Increase in scour depths at rear pier is mainly due to the combined action of 'shed vortices' from the front pier and compression of the 'horseshoe vortices' between the piers. Evidently, the combined action of shed vortices and compression of horseshoe vortices between the front and rear piers dominate over the sheltering effect of front pier. As evident in figure 3 when the two piers are separated from each other, the maximum scour depth at rear pier occurs at radial pier spacing $R / b=3$. At pier spacing $6<R / b<12$, the scour depth at front and rear piers becomes fairly constant and close to the scour depth that occurs at an isolated pier. Therefore, rear pier should be placed at pier spacing in the range $6<R / b<12$.
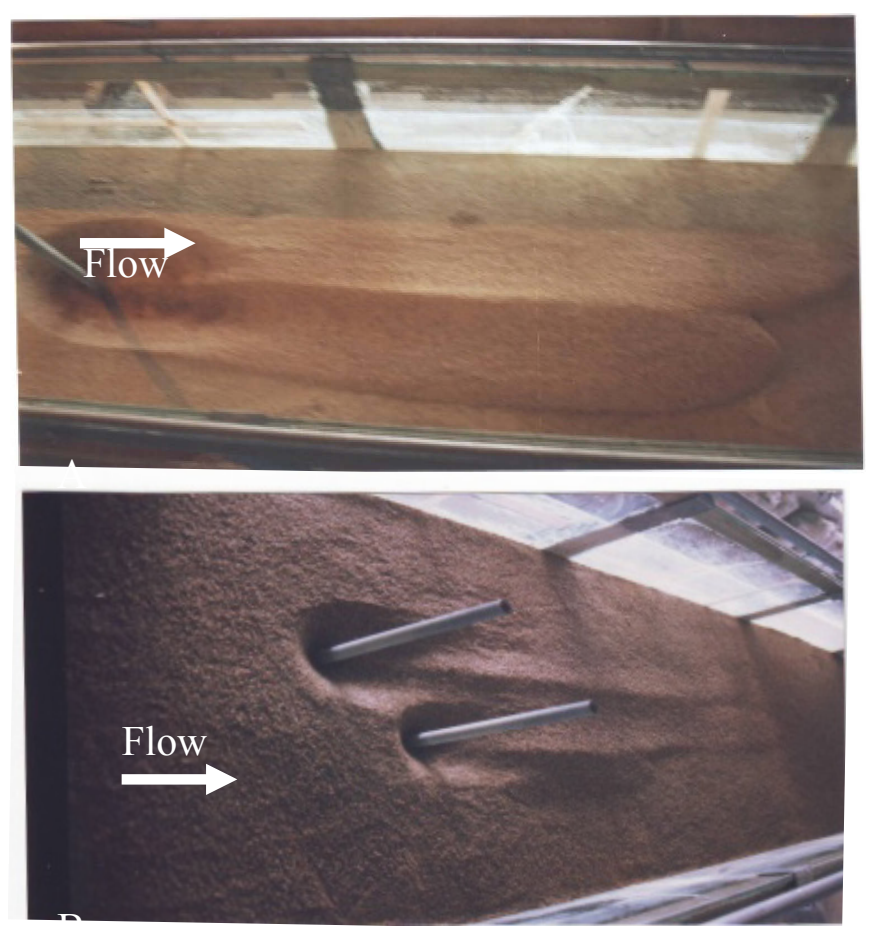

Figure 2. Scour and deposition patterns around two piers aligned at constant angle $45^{\circ}$ and varying radial pier spacings $R / b \quad \begin{array}{ll}\text { (A) } R / b=0 & \text { (B) } R / b=8\end{array}$

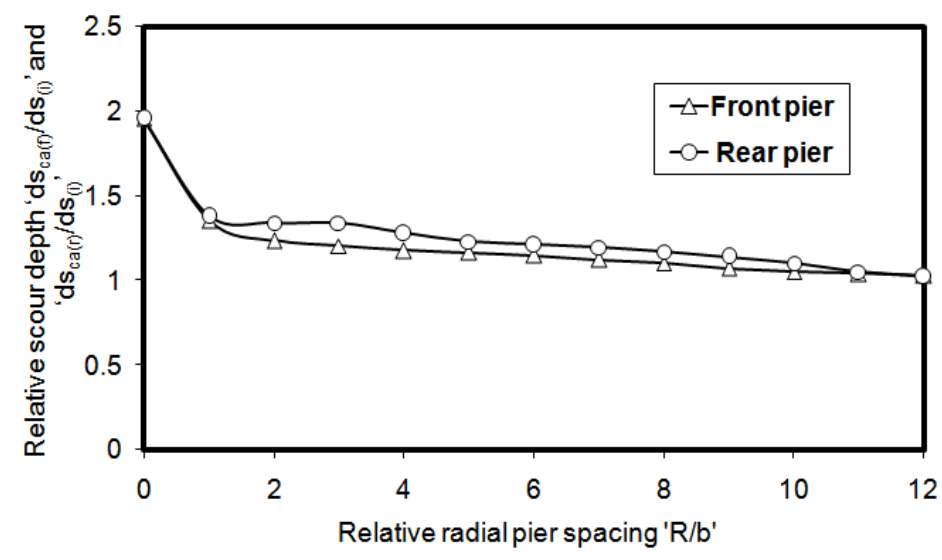

Figure 3. Variation of scour depth at front and rear piers with radial pier spacing

Therefore, rear pier should be placed at pier spacing in the range $6<R / b<12$. At pier spacing $6<R / b<12$, the scour depth at front and rear piers becomes fairly constant and close to the scour depth that occurs at an isolated pier. Therefore, rear pier should be placed at pier spacing in the range $6<R / b<12$. 
Also, maximum difference between the scour depths at front and rear piers is observed at radial pier spacing $R / b=3$. For spacing $R / b>3$, the difference between the scour depths at front and rear piers decreases and the scour depths merge into one another at $R / b=12$ which equals to the scour depth that is observed at an isolated pier.

Scour profiles through front and rear piers are plotted for ideal pier spacings as shown in figure 4(a, b).

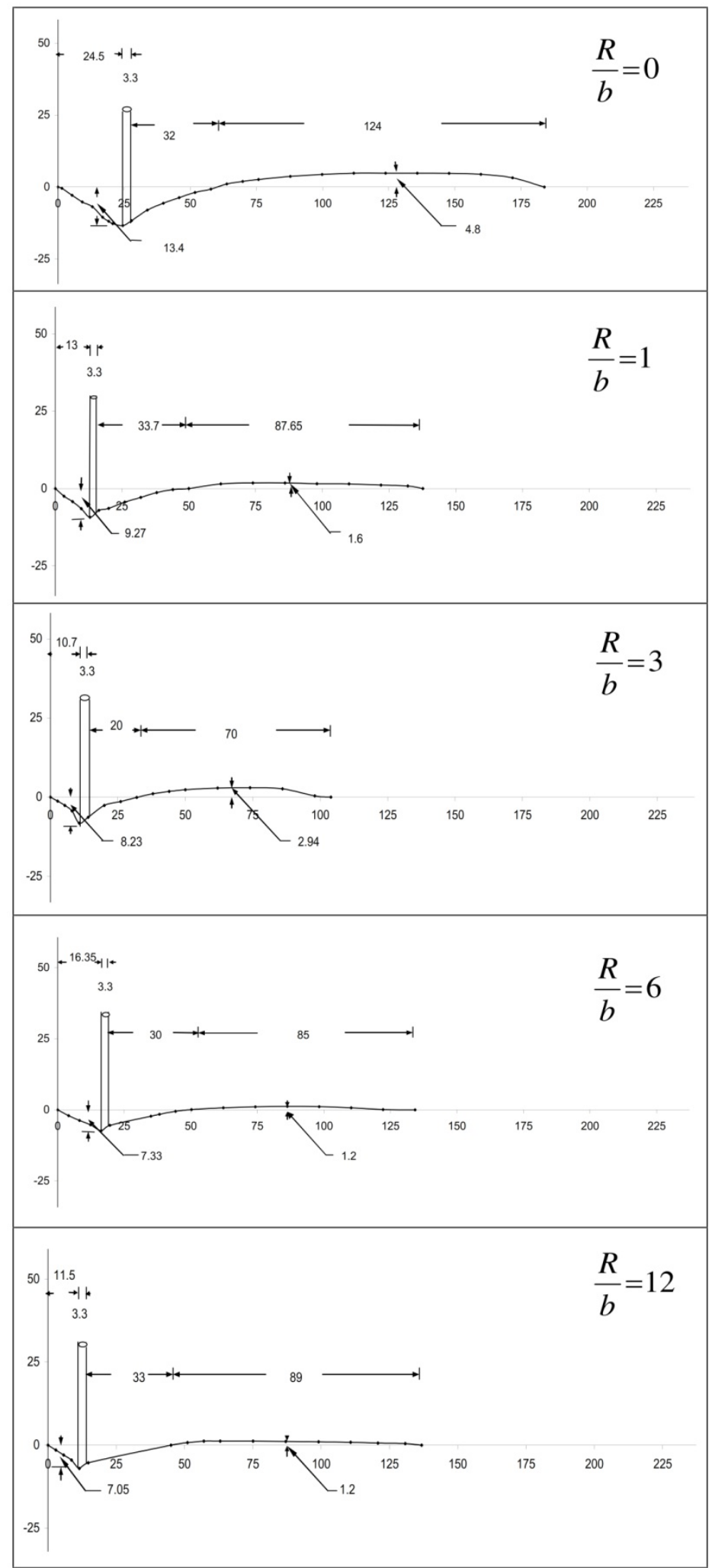

Figure 4 (a) . Longitudinal scour profiles through front pier

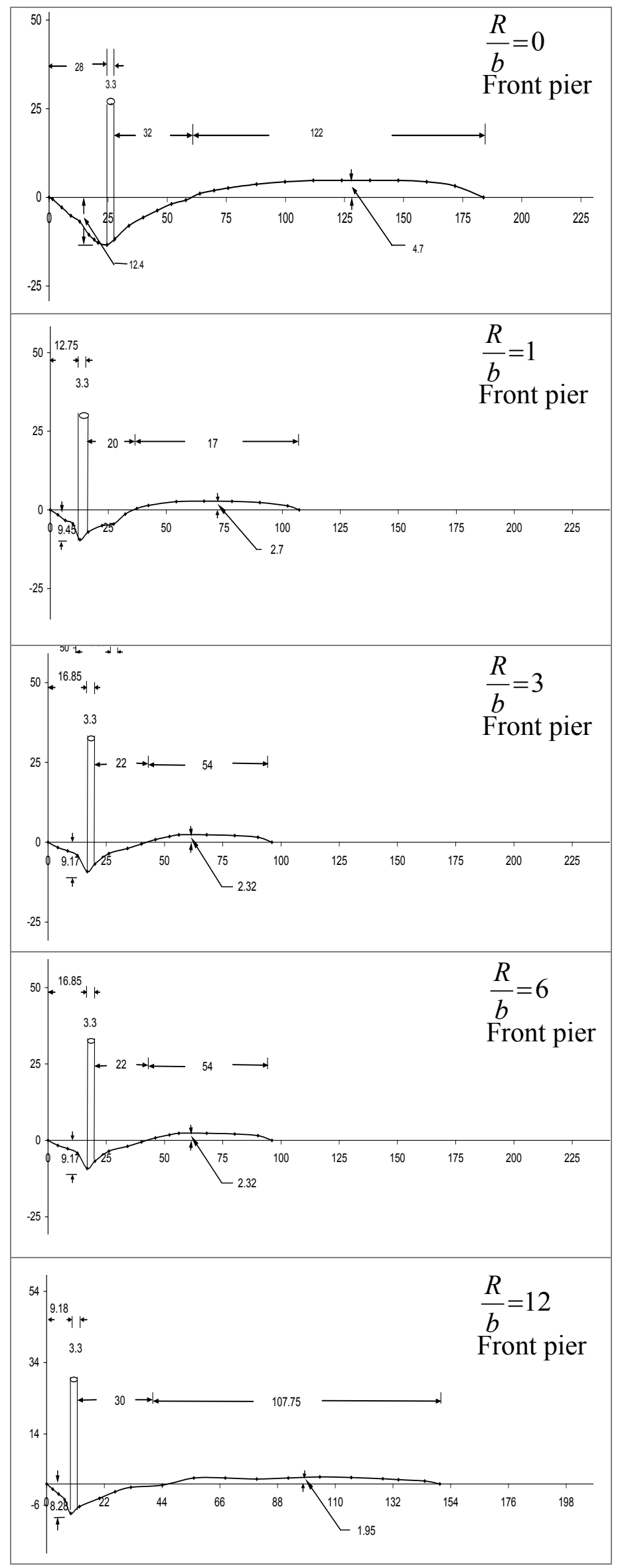

Figure 4 (b) . Longitudinal scour profiles through rear pier 
In order to analyze the results obtained from present experimental data on local scour around front and rear piers placed at varying radial pier spacing ' $R / b$ ' and having their line of centres at $45^{\circ}$ to the approach flow, the longitudinal profile of scour for some distinctive cases are plotted for varied radial pier spacings ' $R / b$ ' and are shown in figure $4(a, b)$. It can be seen that the longitudinal profiles of scour start getting separated from one another at radial pier spacing $R / b=11$, however, the length of the profile of rear pier remains smaller than that of the front pier. As the radial pier spacing $R / b$ approaches to 12 , the lengths of longitudinal profiles become almost similar to that of an isolated pier indicating that the two piers being freed from mutual interference.

\section{CONCLUSIONS}

The scouring around two piers having their line of centers at an angle $45^{\circ}$ to the approach flow is affected by several effects reinforcing, sheltering shed vortices and compression of horseshoe vortices and depending on the radial spacing between the piers, there is dominance of some effects over the other. The effect of shed vortices remains dominant between the two piers due to which scour depth at rear pier remains deeper at short radial pier spacings. However, as radial pier spacing increases, shed vortices originating from the front pier fail to reach the rear pier and thus become ineffective in increasing the scour depth at rear pier. At $R / b=0$, scour depth is deeper than the twice of the scour depth at an isolated pier. however, at $R / b=1$, the scour depth at front and rear piers swiftly decreases but still remains $35 \%$ and $38 \%$ deeper than that at an isolated pier. At $R / b$ $>1$, the scour depth at rear pier gradually decreases and approaches to that at isolated pier at $R / b=12$. Based on the results achieved in this part of present investigation, it can be concluded that the downstream pier should be placed at pier spacing in the range $6<R / b<12$ since the effect of vortex shedding produced by upstream pier is reasonably less in this range of pier spacings.

\section{REFERENCES}

Babaeyan-Koopaei, K. and Valentine, E. M. (1999). Bridge pier scour in self-formed laboratory channels, the XXVIII IAHR Congress, p. 22-27

Basak, V. Baslamish, Y. and Ergun, O. (1975). Maximum equilibrium scour depth around linear-axis square cross-section pier groups, report No. 583, State hydraulic works, Ankara, Turkey, (in Turkish).

Breusers, H.N.C. and Raudkivi, A.J. (1991). Scouring, Hydraulic Structure Manual, I.A.H.R., Balkema, Rotterdam, Netherlands.
Elliot, K.R. and Baker, C.J. (1985). Effect of Pier spacing on scour around bridge piers, Journal of Hydraulics Divn., Proc. ASCE, Vol. 111, No. 7, p. 1105-1109.

El-Taher, R.M. (1984). Experimental study on the interaction between a pair of circular cylinders normal to a uniform shear flow, J. Wind Eng. Ind. Aerodyn. 17, p. 117-132.

El-Taher, R.M. (1985). Flow around two parallel circular cylinders in a linear shear flow. J. Wind Engg. Ind. Aerodyn. Vol. 21, p. 251-272.

Garde, R.J. (1961). Local bed variation at bridge piers in alluvial channels, University of Roorkee research journal, Vol. 4, No. 1 ,

Garde, R.J. and Kothyari, U.C. (1995). State of art report on scour around bridge Piers, Pune, India.

Hannah, C.R. (1978). Scour at pile groups, University of Canterbury, N.Z., Civil Engineering Research Rep. No. 78-3, 92.

Kothyari, U.C. (1989). Scour around bridge piers, Ph.D. Thesis, Univ. of Roorkee, Roorkee, India.

Melville, B.W. And Chiew, Y.M. (1999). Time scale for local scour at bridge piers, J. Of Hydr. Engrg., Asce, 125(1), p. 59-65.

Mubeen Beg, (2008). Effect of Mutual interference of bridge piers on local scour, PhD Thesis, Department of Civil Engineering, Aligarh Muslim University, Aligarh, India.

Shah, B.P. (1988). Interference effects on scour depth around bridge piers, M.Tech. Thesis, Department of Civil Engineering, Indian Institute of Technology, Kanpur, India.

Timonoff, V.E. (1929). Experiments on the spacing of bridge piers in the case of parallel bridges, Hydraulic laboratory practice, edited by J.R. Freeman, Am. Soc. of mech. engrs. New York.

Vittal, N., Kothyari, U.C. and Haghighat, M. (1994). Clear water scour around bridge piers Group, J. Hydr. Engrg, ASCE, 120(11), p. 1309-1318. 